\title{
MULTI-FUEL POWER PLANT AS A ELEMENT OF BACK-UP ENERGY SUPPLY OF FARMING FACILITIES ${ }^{1}$
}

\author{
Aleksandr Korotkova ${ }^{\mathrm{a}}$, Andrey Palichyn ${ }^{\mathrm{b}}$, Petr Savinykh ${ }^{\mathrm{c}}$, Wacław Romaniuk ${ }^{\mathrm{d}}$, \\ Kinga Borek ${ }^{\mathrm{d}}$, Jan Barwicki ${ }^{\mathrm{d}}$ \\ a SPK, "Kolhoz Angoda"Company, Kaduyskiy Region, Russia \\ b FGBOU Vologckaya GMHA NV. Vereshagina, Vologda, Russia \\ c GNU NIISH-SH North-East Scientific and Research Institute of Agriculture N.V. Rudnitshy, Kirov, \\ Russia \\ ${ }^{d}$ Institute of Technology and Life Sciences in Falenty, Warsaw Branch, Poland \\ *Corresponding author: e-mail: w.romaniuk@itp.edu.pl
}

\begin{tabular}{l}
\hline ARTICLE INFO \\
\hline Article history: \\
Received: November 2018 \\
Received in the revised form: \\
Decemberr 2018 \\
Accepted: March 2019 \\
\hline Key words: \\
natural gas, \\
utilization, \\
alternative energy supply, \\
electricity generation, \\
new development, \\
agriculture production
\end{tabular}

\begin{tabular}{l} 
ABSTRACT \\
\hline Paper presents research concerned utilization of natural \\
gas in a liquid state as a new source of electrical energy \\
generation in country side areas of Russia to use it in \\
a small family farms and bigger agriculture enterprises. \\
The experiment shows that alcohol and gasoline are \\
more expensive products to be a source for electricity \\
generation as a reserve energy supply in agriculture \\
production areas of the country. Introduction of natural \\
gas generator as an alternative fuel makes possible to \\
produce low cost of electrical energy in any part of the \\
country, what gives great potential to alternative energy \\
supply, but especially for agriculture production on \\
small households and also bigger enterprises
\end{tabular}

\section{Введение}

На фоне проводимых реформ в энергетическом секторе России, вопросы качества электроснабжения потребителей в последнее время вновь становятся актуальными. Это связано, как с объективными факторами, такими как: сезонность при производстве и потреблении электрической энергии, техническим состоянием распределительных электросетей, погодно - климатическими условиями и т.д., так и

1 Исследования выполненные в рамках проекта "Междисциплинарные исследования по повышению энергоэффективности и увеличению доли возобновляемых источников энергии в энергетическом балансе польского сельского хозяйства", Номер контракта ВIOSTRATEG1/269056/5/NCBR/2015 11.08.2015 год, финансируемый по Национальный Центр Исследований и Разработок в рамках программы BIOSTRATEG1. 
A. Korotkov, A. Palichyn, P. Savinykh, W. Romaniuk, K. Borek, J. Barwicki

чисто субъективными, их можно охарактеризовать как экономические. Особенно остро вопрос бесперебойного электроснабжения стоит для потребителей 3 категории надежности электроснабжения, как правило, не имеющей резервных схем электроснабжения и собственных генерирующих мощностей. К ним в основном относится коллективный и частный жилой сектор, сельскохозяйственные предприятия и коммерческие структуры малого бизнеса (Fernandez-Dacosta et al., 2019; Morozov, 2011; Budzko, 2000; Korotkov et al., 2018).

В относительно небольших крестьянских и фермерских хозяйствах, базовым профилем производства которых является животноводство, основные технологические процессы связаны с применением электрической энергии: освещение помещений в период обслуживания животных, доение, первичная обработка молока и его хранение, функционирование автоматических систем тепло и водоснабжения, навозоудаления. (Bicer and Dincer, 2018; Morozov, 2011; Gabitov, 2017) Нарушение электроснабжения приводит к простоям технологического оборудования, нарушениям технологических и физиологических циклов у животных, что в конечном итоге негативно отражается на экономических показателях производства.

\section{Материалы и методы}

Для минимизации негативного влияния на производственные процессы перебоев в электроснабжении крестьянские и фермерские хозяйства вынуждены обзаводиться собственными электростанциями. Как правило, это маломощные (до 5 кВт), бытовые электростанции с приводом от поршневого двигателя внутреннего сгорания (ДВС) с искровым зажиганием, который использует в качестве топлива бензин или природный газ. Реже применяются электростанции с приводом от дизельного ДВС.

Изначально высокая стоимость топлива для ДВС делает нерентабельной производство электроэнергии и снижает конкурентоспособность производимой на ее основе продукции. Эти финансовые издержки могут быть оправданы только в условиях чрезвычайных ситуаций, когда необходимо сохранить технологические циклы производства. Большой резерв снижения себестоимости кВт*часа электроэнергии получаемой от автономной электростанции заключается в использовании более дешевых топлив, в том числе и альтернативных. Которые могут быть произведены из местных биоресурсов, карбоносодержащих отходов сельского хозяйства и промышленности. (Korotkov, 2018; Mahla, 2018; Santanu et al., 2018).

В проведенных экспериментальных исследованиях ставилась задача по выявлению закономерности между ценой и видом моторного топлива для ДВС, и стоимостью кВт*часа электроэнергии получаемой от автономной электростанции. В экспериментах по многотопливному циклу работы использовались электростанция GG 2700 с одноцилиндровым ДВС 1Ч 6,8/5,4 и электростанция АБ-4-О/230-M1 с двухцилиндровым ДВС 24 7,2/6,0. Эксплуатация осуществлялась на бензине АИ 92, в качестве жидкого товарного моторного топлива; сжиженного природного газа (летняя пропан - бутановая смесь 50/50), в качестве газообразного товарного моторного топлива; этилового спирта $\left(\rho=0,95 \quad \Gamma^{\cdot} \mathrm{cm}^{-3}\right)$, в качестве жидкого 
Multi-fuel power plant...

альтернативного моторного топлива и генераторного газа, в качестве альтернативного газообразного моторного топлива.

Поисковые эксперименты показали, что современные ДВС электростанций удовлетворительно работают, как на традиционных, так и на альтернативных видах топлива, без модернизации систем питания и зажигания. Но, при этом, наблюдается существенное падение мощности ДВС, которое на некоторых видах альтернативного топлива достигает 60\% (Zubakin 2016, 2017). Для улучшения адаптивности ДВС электростанции GG 2700, при работе на различных видах топлива, штатная система зажигания от магдино, была заменена доработанными элементами электронной системы зажигания от двигателя ВАЗ - 2108, что позволило в динамике изменять угол опережения зажигания в пределах $50^{\circ}$. Штатный бензиновый карбюратор заменен на многотопливный карбюратор 168F-СУГ (газ/бензин). Общий вид модернизированной системы зажигания приведен на рисунке 1, а общий вид установленного многотопливного карбюратора 168F-СУГ и смесителя для генераторного газа на рисунке 2.

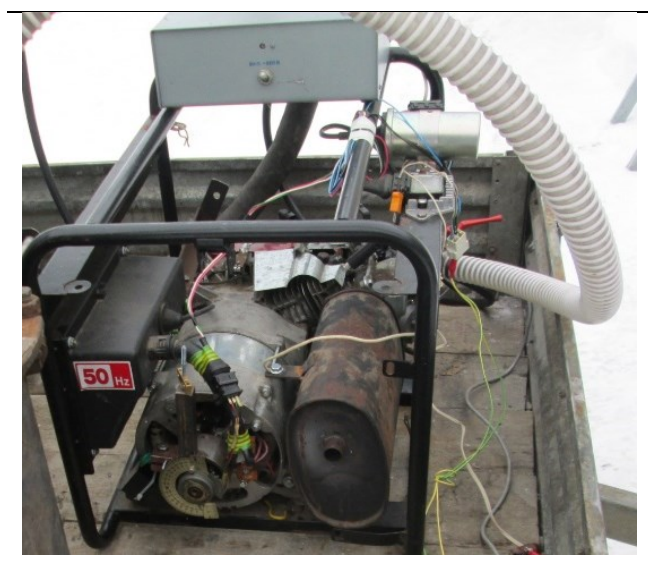

Рисунок 1. Общзий вид модернизированной системьз зажигания

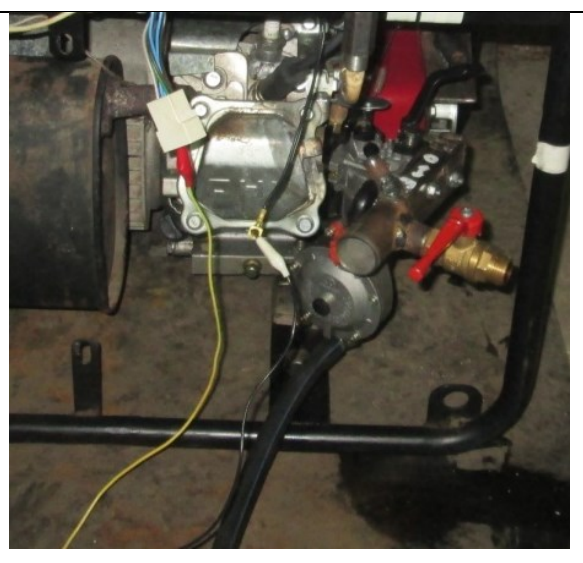

Рисунок 2. Общий вид многотопливного карбюратора 168 -СУГ и смесителя для генераторного газа

Штатная система зажигания ДВС электростанции АБ-4-О/230-М1 от магнето изменению не подвергалась, так как при переходе с одного на другой вид топлива позволяет вручную корректировать угол опережения зажигания (УОЗ). Штатный бензиновый карбюратор К - 16М заменен на многотопливный карбюратор 188F-СУГ (газ/бензин). Общий вид системы зажигания, установленного многотопливного карбюратора 188F-СУГ и смесителя для генераторного газа приведен на рисунке 3.

Для производства генераторного газа в экспериментах использовался газогенератор с параметрическим управлением процессом газификации в плоскости фурменного пояса (Ospretsov et al., 2015). Общий вид экспериментальной газогенераторной установки приведен на рисунке 4. 
A. Korotkov, A. Palichyn, P. Savinykh, W. Romaniuk, K. Borek, J. Barwicki

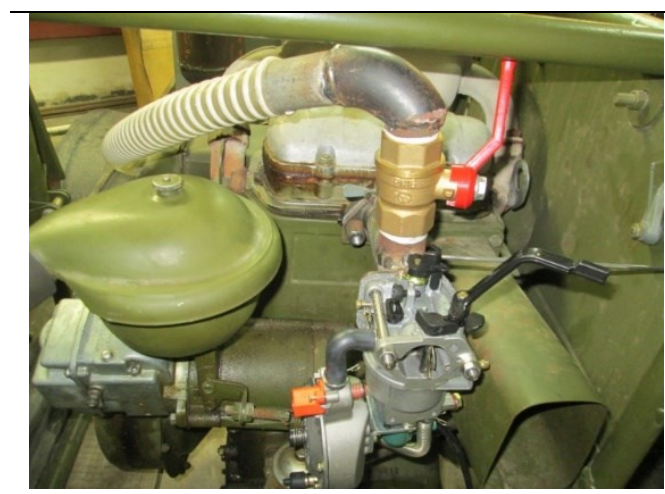

Рисунок 3. Общчий вид системы зажигания, многотопливного карбюратора 188 F-СУГ и смесителя для генераторного газа

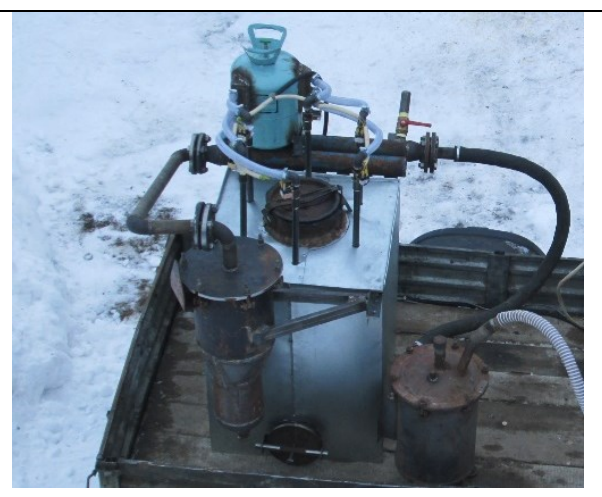

Рисунок 4. Общий вид экспериментальной газогенераторной установки

Для поддержания частоты вращения коленчатого вала ДВС электростанции в рабочем диапазоне используются штатные центробежные регуляторы частоты вращения. Общий вид электростанций с экспериментальной газогенераторной установкой приведен на рисунках 5 и 6.

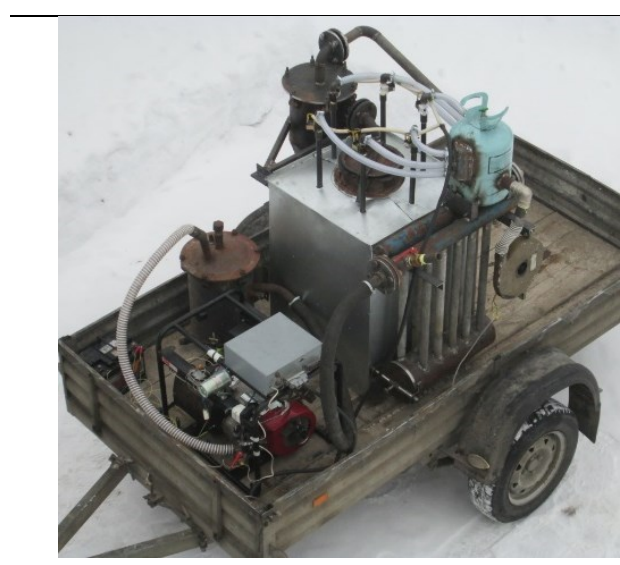

Рисунок 5. Общчий вид экспериментальной газогенераторной установки с электростанщией $G G-2700$

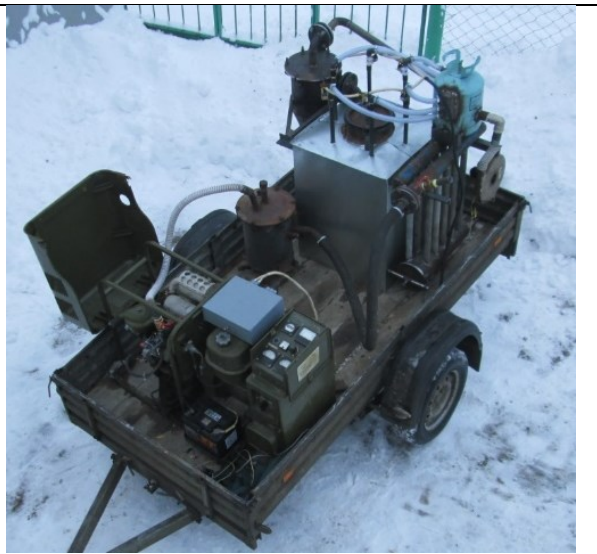

Рисунок 6. Общчий вид экспериментальной газогенераторной установки с электростанциией $А Б-4-O / 230-M 1$ 
Multi-fuel power plant...

\section{Результаты и обсуждение:}

Оценка экономической эффективности выработки 1 кВт.ч ${ }^{-1}$ электроэнергии произведена на примере электростанций GG - 2700 и АБ-4-О/230-M1 с учетом того, что все топлива приобретаются по коммерческой цене. При этом не учитываются накладные расходы, амортизация оборудования и фонд оплаты труда (Korotkov 2018).

За исходные данные для расчетов приняты:

- стоимость бензина марки А - 92-42 руб. $\cdot$ литр ${ }^{-1}$;

- стоимость сжиженного газа (летняя пропан - бутановая смесь 50/50) - 19,5 руб. литр ${ }^{-1}$;

- стоимость этилового спирта $\rho=0,95 \Gamma^{\cdot} \mathrm{cm}^{-3}-190$ руб. $\cdot$ литр ${ }^{-1}$;

- стоимость смеси древесной щепы (лиственных и хвойных пород), воздушной влажности, без антисептической обработки, используемой для изготовления арболитных стройматериалов -470 руб. м $^{-3}$.

Динамика изменения стоимости производимой электроэнергии в зависимости от мощности и вида топлива для электростанций $\mathrm{GG}-2700$ приведена на рисунке 7, а для электростанции АБ-4-О/230-М1 на рисунке 8.

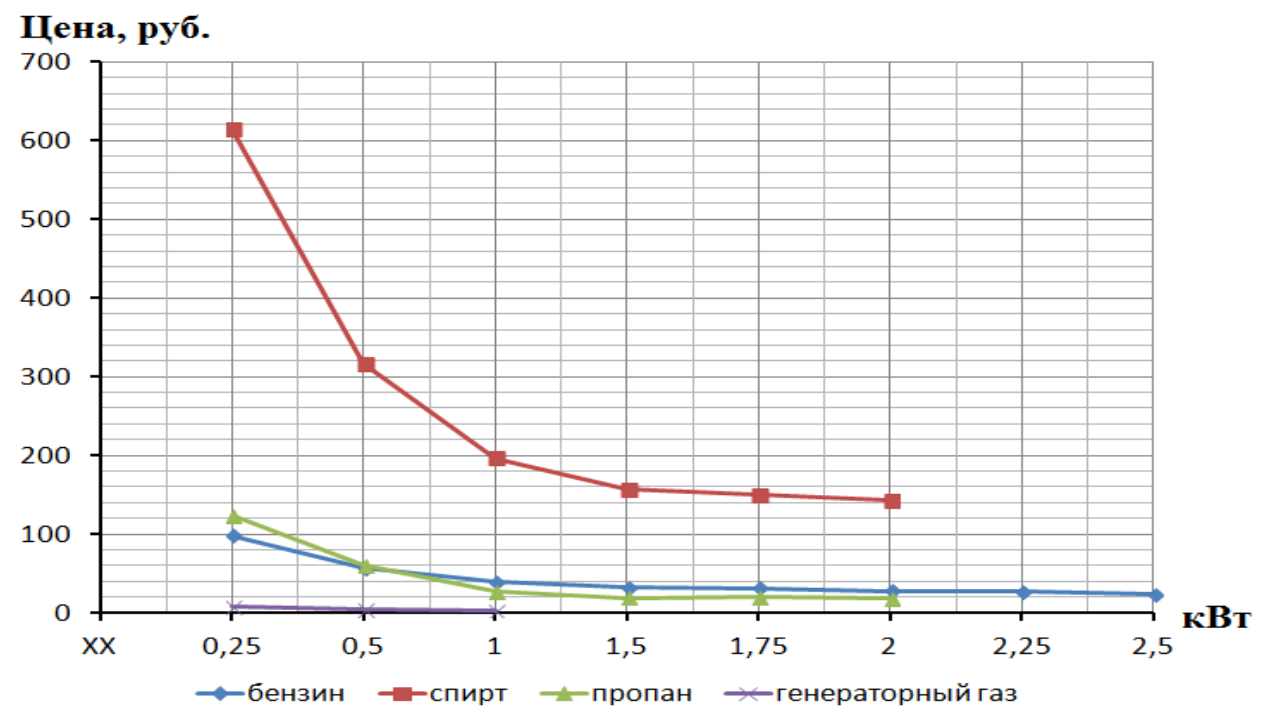

Рисунок 7. Динамика изменения стоимости производимой электроэнергии электростанций $G G-2700$

Результаты исследований по стоимости кВт.часа производимой электроэнергии на различных видах топлива электростанциями сведены в таблицу 1. 
A. Korotkov, A. Palichyn, P. Savinykh, W. Romaniuk, K. Borek, J. Barwicki

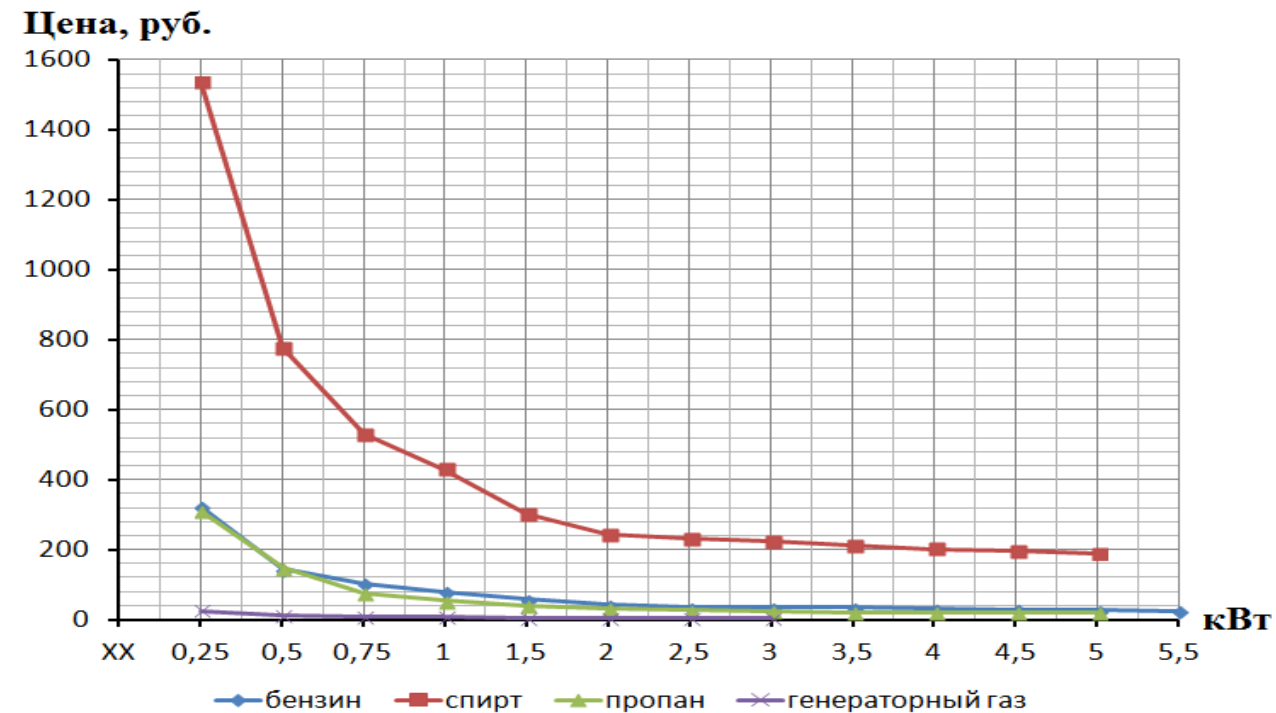

Рисунок 8. Динамика изменения стоимости производимой электроэнергии для электростанщии АБ-4-O/230-M1

Таблица 1.

Стоимость производства кВт •часа электроэнергии

\begin{tabular}{lcccccccc}
\hline \multirow{2}{*}{$\begin{array}{l}\text { гл., } \\
\text { кВт. час }\end{array}$} & $\begin{array}{c}\text { бензин, } \\
\text { руб. }\end{array}$ & $\begin{array}{c}\text { спирт, } \\
\text { руб. }\end{array}$ & $\begin{array}{c}\text { пропан, } \\
\text { руб. }\end{array}$ & $\begin{array}{c}\text { ген.газ, } \\
\text { руб. }\end{array}$ & $\begin{array}{c}\text { бензин, } \\
\text { руб. }\end{array}$ & $\begin{array}{c}\text { спирт, } \\
\text { руб. }\end{array}$ & $\begin{array}{c}\text { пропан, } \\
\text { руб. }\end{array}$ & $\begin{array}{c}\text { ген.газ, } \\
\text { руб. }\end{array}$ \\
\hline 0,25 & 98,28 & 614,4 & 123,6211 & 7,7922 & 322,56 & 1536 & 309,05 & 25,57 \\
0,5 & 56,7 & 316,8 & 60,0936 & 4,4955 & 143,64 & 777,6 & 147,5 & 11,38 \\
1 & 39,06 & 196,8 & 27,47136 & 3,0969 & 103,32 & 531,2 & 74,15 & 8,19 \\
1,5 & 31,92 & 156,8 & 19,45888 & - & 79,38 & 429,6 & 53,31 & 6,29 \\
1,75 & 31,08 & 149,4857 & 19,6224 & - & - & - & - & - \\
2 & 27,405 & 142,8 & 18,02808 & - & 57,54 & 300,8 & 39,48 & 4,56 \\
2,25 & 27,06667 & - & - & - & 41,89 & 243,6 & 30,75 & 3,32 \\
2,5 & 23,184 & - & - & - & 34,77 & 230,4 & 26,09 & 2,75 \\
3 & - & - & - & - & 34,23 & 224,8 & 23,32 & 2,71 \\
3,5 & - & - & - & - & 35,28 & 212,57 & 21,46 & - \\
4 & - & - & - & - & 31,5 & 202,2 & 20,28 & - \\
4,5 & - & - & - & - & 29,4 & 194,66 & 19,36 & - \\
5 & - & - & - & - & 26,96 & 189,6 & 19,31 & - \\
5,5 & - & - & - & - & 25,54 & - & - & - \\
\hline
\end{tabular}


Multi-fuel power plant...

Графики наглядно иллюстрируют высокую стоимость выработанной электроэнергии на спирте и бензине. Работа на сжиженном природном газе снижает стоимость электроэнергии за счёт относительно невысокой стоимости топлива. Применение генераторного газа в качестве альтернативного топлива для ДВС электростанции позволяет привести стоимость 1 кВт*час к значениям сопоставимым с получением электроэнергии от единой энергетической системы России. Стоимость 1 кВт-час электрической энергии для потребителей на оптовом рынке электроэнергии в Вологодской области составляет 3,2 рубля. С учетом затрат на доставку, обслуживание сетевого хозяйства и вознаграждения за посреднические услуги себестоимость 1 кВт-час электрической энергии для конечного потребителя, в лице сельскохозяйственных организаций, возрастает до 8,41 рубля.

\section{Заключение:}

Анализ графического материала и таблицы 1 позволяет сделать ряд выводов:

1. Изначально высокая стоимость товарного моторного топлива для ДВС, за счет явных и скрытых налогов, сборов, акцизов и пошлин делает нерентабельной производство электроэнергии на автономных электростанциях. Это повышает финансовую нагрузку на крестьянские и фермерские хозяйства, использующие автономные электростанции в качестве резервного источника электроснабжения, снижает конкурентоспособность производимой ими продукции.

2. Большой резерв снижения себестоимости кВт·часа электроэнергии получаемой от автономной электростанции заключается в использовании более дешевых моторных топлив, в том числе и альтернативных. Например, в применении сжатых и сжиженных природных газов, биогаза, а также генераторного газа произведенного из местных биоресурсов, карбоносодержащих отходов сельского хозяйства и промышленности.

3. Цена производства электрической энергии на автономных генерирующих мощностях относительно небольшой мощности (до 5 кВТ), с использованием генераторного газа в качестве моторного топлива вполне сопоставима с ценой приобретения электроэнергии от «гарантированных поставщиков» единой энергетической системы России (Korotkov, 2018; Gabitov, 2017)

4. Повысить инвестиционную привлекательность систем автономной генерации для крестьянских и фермерских хозяйств возможно за счет снижения стоимости исходного сырья используемого для производства генераторного газа, т.е. использовать не только местные относительно дешевые энергоресурсы, но и осуществлять переработку отходов сельскохозяйственного и промышленного производства. Кроме этого в процессе производства создаются новые коммерческие продукты с добавленной стоимостью (тепловая энергия и концентрированное минеральное удобрение), что также способствует повышению рентабельности технологического цикла производства (Kipriyanov, 2014). 
A. Korotkov, A. Palichyn, P. Savinykh, W. Romaniuk, K. Borek, J. Barwicki

\section{Литература}

Bicer, Y., Dincer, I. (2018). Life cycle environmental impact assessments and comparisons of alternative fuels for clean vehicles. Resources, Conservation and Recycling, 132,141-157.

Budzko, I.A. (2000). Elektrosnabzenye selskovo hoziaystva. Kolos, Moscow, ISBN 5-10-0031172-7.

Fernandez-Dacosta, C., Shen, L., Schakel, W., Ramirez, A., Kramer, G.J. (2019). Potential and challenges of low-carbon energy options: Comparative assessment of alternative fuels for the transport sector. Applied Energy, 15, 590-606.

Gabitov, I.I. (2017). Energeticheskiy kompleks s gasogeneratornoy ustanovkoy dla malyh selskohazaystrennyh proizvodetv. Teoreticheskij i nauchno-prakticheskiy zurnal, 91, 14-23.

Kipriyanov, F.A. (2014).Parametricheskiy gazogenerator s objemnym regulirobaniem protsesa gazifikatsyi. Molochnohozyaystvenny vestnik, 7(16), 84-89.

Korotkov, A.N. (2018). Sovershenevovanye konstruktsyi i optimimizatsya konstruktivna technologicheskih parametrov gazogenieratorno ustanovkiy. Nauchno-kvalifikotsionoya robota na soyskanye stepeni, Moscow.

Korotkov, A.N. Plotnikova, J.A., Palitsyn, A.V., Savinykh, P.A. (2018). Use of liquid cattle manure as an alternative fuel for piston internal combustion engine of a power plant. Problems of intensification of animal production including environment protection and alternative energy production as well as biogas. Warsaw, ISBN 978-83-65426-35-2, 88-93.

Mahla, S.K., Singla, V., Sandhu, S.S., Dhir, A. (2018). Studies on biogas-fuelled compression ignition engine under dual fuel mode. Environmental Science and Pollution Research, 25, 9722-9729.

Morozov, N.M. (2011). Organizacjonno-ekonomicheskije i tehnologicheskije osnovy mehanizatsyi $i$ avtomatyzatsyi. FGBNY Rosinformagrotech, Moscow.

Ospretsov, V.N., Zubakin, A.S., Palitsyn, A.V., Korotkov, A.N. (2015). Gazogenerator. FGBOU Vologckaya GMHA NV. Vologda. Russia. Patent description, 2013132317. No 2555486 from 11.07.2013. Published 10.07.2015.

Santanu, D., Avinash, K.A., Moholkar, V.S., Thallada, B. (ed.). (2018) Coal and Biomass Gasification. Recent Advances and Future Challenges. Springer Nature Singapore Pte Ltd., Singapore, ISBN 978-981-10-7334-2.

Zubakin, A.S. (2016). Isledovaniye roboty DVS bytoroy elektrostan na alternativnych bidah topliva, s tselyu uluchsheniya kachestvennyh pokazateley vyrabatyvayemoy energetiki. Uspehi sovremennoy nauki, 12(8), 88-92.

Zubakin, A.S. (2017). Opredeleniye optimalnogo ugla operezhnaya zozhgoniya dvigateliya $1 \mathrm{ch}$ $6,8 / 5,4$ pri rabote na generatornom gaze i smesti benzina i generatornogo. Uspehi sovremennoy nauki, 7, 132-166. 


\section{ELEKTROWNIA WIELOPALIWOWA JAKO ELEMENT DOSTARCZANIA ENERGII ZAPASOWEJ DO OBIEKTÓW ROLNICZYCH}

Streszczenie. W pracy przedstawiono badania dotyczące wykorzystania gazu ziemnego w stanie ciekłym jako nowego źródła wytwarzania energii elektrycznej w rosyjskich obszarach wiejskich $\mathrm{w}$ celu wykorzystania go $\mathrm{w}$ małych gospodarstwach rodzinnych i większych przedsiębiorstwach rolniczych. Eksperyment pokazuje, że alkohol i benzyna są droższymi produktami, które mogłyby być brane pod uwagę do wytwarzania energii elektrycznej jako energii zapasowej w różnych obszarach produkcji rolnej kraju. Wprowadzenie generatora gazu ziemnego jako paliwa alternatywnego umożliwia wytwarzanie taniej energii elektrycznej w dowolnej części kraju, co daje ogromny potencjał dla alternatywnych dostaw energii, ale szczególnie dla produkcji rolnej w małych gospodarstwach domowych, a także w miarę potrzeb w większych przedsiębiorstwach rolnych.

Słowa kluczowe: gaz ziemny, alternatywne dostawy energii, wytwarzanie energii elektrycznej, nowa technologia, produkcja rolna

Identification data Authors:

$\begin{aligned} \text { Aleksandr Korotkov } & \text { https://orcid.org/0000-0002-8778-1692 } \\ \text { Andrey Palichyn } & \text { https://orcid.org/0000-0001-5901-5678 } \\ \text { Petr Savinykh } & \text { https://orcid.org/0000-0002-5668-8479 } \\ \text { Wactaw Romaniuk } & \text { https://orcid.org/0000-0001-7776-9940 } \\ \text { Kinga Borek } & \text { https://orcid.org/0000-0002-0171-7498 } \\ \text { Jan Barwnicki } & \text { https://orcid.org/0000-0002-5437-5284 }\end{aligned}$

